provided they differ sufficiently in properties. Short chapters on the purification of $p$-xylene by partial freezing and on the purification of isopropylbenzene by preparative gas-liquid chromatography record the processing of relatively small samples. The discussion on fractional distillation (nineteen pages) emphasizes the steps which must be taken to protect the samples against contamination by the atmosphere. The author of the account of dry-column chromatography expresses the hope that workers will begin to use this technique. The importance of the nature of the impurities in the starting material for the preparation of pure water is emphasized and the production of specimens of low electrical conductivity and for use in the electronics industry are considered. The difficulties in the preparation of pyrogen-free and particle-free water are mentioned and the chapter closes with the statement, "Ultrapure macroscopic water can be considered to contain microparticles based on the isotopes of hydrogen and oxygen". However, changes in isotopic composition of water during purification are not discussed and the preparation of samples of precise density is, therefore, not reported. There is a straightforward account of the purification and analysis of cholesterol.

The section on "Handling" and "Containment" would have been better written under a single heading because the chapter "Contamination Problems in Trace-Element Analysis and Ultrapurification" presents useful information on storage vessels which is covered again in a slightly different form in the chapters "Glass Containers for Ultrapure Solutions" and "Vitreous Silica". A reader of "Airborne Contamination" would have to look elsewhere for details but is provided with only nine references for this purpose. The chapter entitled "Ceramics" discusses eighteen ceramics in nine pages.

The twenty-four page chapter on "High-Purity Chemicals-A Challenge to Practical Analysis" summarizes briefly the determination of major and minor constituents and is written from much first hand experience. The titles of chapters on "Emission Spectroscopy", "Flame Spectrophotometric Trace Analysis", "Neutron-Activation Analysis", "Visible Spectrophotometry" and "Coulometric Titration" sufficiently indicate their contents.

Much tabulated data is given but the quality of presentation is very uneven; some chapters are difficult to read and are incomprehensible in places due to errors-for example, "A good syringe pump, set at the optimum flow rate, is invaluable for ironing and partial clogging and airflow inconsistencies".
The book jacket states that "This work is directed to all those working in research, development, or analysis of ultrapure products-electronic engineers, analytical chemists, clinical chemists, geochemists, oceanographers, material scientists, and environmental researchers". In my opinion this volume of loosely coordinated chapters attempts too much and as a result many workers in the above mentioned fields may decide to follow the advice given to analysts on page 527, "Specialized applications to specific problems must be sought in sources best known to the individual analyst". Unfortunately most applications of ultrapurity are specialized. E. F. G. HERINGTON

\section{Air Pollution}

Air Pollution. By W. L. Faith and A. A. Atkisson. Second Edition. Pp. viii + 393. (Wiley: New York and London, December 1972.) £8.65.

WHEN I edited a book with the same title in 1957, public enemy number one, from the point of view of air pollution, was the coal fire, and number two grit and coarse dust, for example, from chain grate stokers. This book illustrates the fact that, in Europe as well as in the USA, public enemy number one is now the internal combustion engine, and number two is $\mathrm{SO}_{2}$. The oxides of nitrogen can undergo a photochemical reaction with unburnt hydrocarbons in conditions of intense sunlight and long standing inversions, and so the car is blamed for the Los Angeles smog and a whole chapter is devoted to photochemical air pollution. The $\mathrm{CO}$ and unburnt and partially burnt hydrocarbons given off by the car are a consequence of bad combustion and so high fuel consumption, whereas, on the contrary, oxides of nitrogen are primarily a consequence of high combustion temperatures and excess combustion air, while lead is emitted because its addition to the fuel provides a cheap way of operating high power compact engines on a large fraction of the total petroleum.

This second edition is changed from the first edition of 1959 in several ways. First, there is an increase in the emphasis on tall stacks, the use of which reduces the local maximum ground level concentration by spreading it further away, but is not a final solution to the problem when there are enough stacks in a region to combine their long distance effects. The main formulae for dispersion were available 15 years ago, but more work is recorded on effects of tall buildings, irregular terrains, inversions, "fumigation" and multiple stacks. Second, an account of the development of air quality standards and emission regulations in the USA is added. Then automobile exhaust in the earlier edition has been extended to cover vehicle testing on chassis dynamometer, pollution control methods, two pages only on diesel exhausts and two on aircraft emissions.

The chapter on "Social Origins of Air Pollution" takes what one can call a five-year forward legal-economic look, but completely fails to take account of what the rest of the world can see, that there is no real solution to the pollution and other problems as long as the USA continues to base its economy on a fuel and other resource consumption which is six times the world average. Pollution Control, treated as a problem in isolation from others, can only lead to such results as the US proposed standards for car exhaust emission, causing the manufacturers to fit afterburners and exhaust gas recyclers which cause an increase in the fuel consumption and the engine size and the effective use of which cannot be ensured for long after the car is used.

M. W. THRING

\section{Degree of Belief}

Probability, Induction and Statistics: The Art of Guessing. By Bruno de Finetti. Pp. xxiv+266. (Wiley: New York and London, November 1972.) $£ 6.50$.

DE FINETTI is perhaps the most brilliant worker in the field of probability this century. His work is little known in Britain because he writes mainly in rather difficult Italian, and because he does not publish in statistical journals, where the main operational material on probability has appeared. Here we have the opportunity to read, in English, about some of his ideas. No one interested in probability should fail to read this book.

His view of probability is that it is always "a measure of the degree of belief of a given subject in the occurrence of an event (proposition)": The book is not written as a unit, but consists of eleven papers divided into three main groups. The first group consists of papers on the operational foundations. His philosophical attitude is essentially behaviouristic, and probability is measured and understood by the subject's attitude to decision problems. In these papers he discusses, amongst other things, how this measurement might be performed. Statisticians who keep saying the prior distribution is unknown should read this section. The next group of papers is concerned with the axiomatic foundations of probability: in particular, whether it is finitely or $\sigma$-additive. This section is really only suitable for the reader equipped with the necessary technical knowledge of measure theory. Frankly it leaves me 